\section{Scheduling delay in suspected cases of oral cancer}

\section{Atraso de agendamento em casos suspeitos de câncer bucal}

Luciana Meneses Souza'

\section{Edgard Michel-Crosato'}

\section{Maria Gabriela Haye Biazevic'}

José Leopoldo Ferreira Antunes"

' Departamento de Odontologia Social da Faculdade de Odontologia da Universidade de São Paulo (FOUSP).

"Departamento de Epidemiologia da Faculdade de Saúde Pública da Universidade de São Paulo (FSP/USP).

Trabalho realizado no Departamento de Odontologia Social da Faculdade de Odontologia da Universidade de São Paulo - FOUSP.

Conflict of interests: None declared.

This investigation was supported by FAPESP (process number 06/07079-8)

Correspondência: Maria Gabriela Haye Biazevic. Departamento de Odontologia Social da Faculdade de Odontologia da USP - FOUSP. Avenida Lineu Prestes, 227 Cidade Universitária. São Paulo, SP CEP 05508-000. E-mail: biazevic@usp.br

\section{Abstract}

The objective of the study was to evaluate scheduling delay of dental exams in the city of São Paulo of patients suspected of having oral cancer. A cross-sectional study was performed in which telephone conversations simulated clinical situations that represented two types of patients: one presenting symptoms suggestive of oral cancer (CA), and another one suggesting the need for prostheses (PR). The scheduling delay was evaluated by the days until an appointment for care; and among public offices, by type of schedule (emergency or routine). Negative binomial regression was used (95\% statistical significance). Five hundred and seventy-five public and private dental offices participated in the study. The mean scheduling delay for the CA group was 2.88 days, and for the PR group, 4.34 days $(\mathrm{p}=0.01)$. The mean scheduling delay was shorter in private dental offices (2.59 days) than in offices that accepted health insurance ( 2.74 days) ( $p=0.01$ ); the delay was shorter when performed by the dentist rather than by the dental assistant, 2.45 versus 4.21 days $(\mathrm{p}=0.01)$. In public services, $69 \%$ of patients in the cancer group were sent to the emergency service. Dental services were accessible for scheduling clinical examinations among patients suspected of having oral cancer.

Keywords: Mouth neoplasms. Dental health services. Human resources. Dental staff. Dentistry. Dental prosthesis. 


\section{Resumo}

O objetivo do estudo foi avaliar o atraso de agendamento de pacientes com suspeita de câncer bucal aos exames odontológicos na cidade de São Paulo. Realizou-se estudo transversal, em que conversações telefônicas simularam situações clínicas, representando dois tipos de pacientes-padrão: um com sintomas sugestivos de câncer bucal e outro com necessidade de prótese. $\mathrm{O}$ atraso do agendamento foi avaliado pelo tempo de agendamento para a consulta e, no caso de estabelecimentos públicos, pelo tipo de agendamento (rotina ou urgência). Utilizou-se regressão binomial negativa (95\% de nível de significância). Participaram do estudo 575 estabelecimentos públicos e privados. O tempo médio, em dias, para o agendamento no grupo câncer foi de 2,88 e no grupo prótese, $4,34(\mathrm{p}=0,01)$. O tempo médio de agendamento foi menor nos consultórios particulares 2,59 que nos conveniados 2,74 ( $\mathrm{p}=0,01)$; quando realizado pelo dentista foi menor do que pelos auxiliares, 2,45 versus 4,21 ( $\mathrm{p}=0,01)$. No serviço público, $69 \%$ dos pacientes do grupo câncer foram encaminhados ao serviço de urgência. Os serviços de atendimento odontológico foram acessíveis com relação ao agendamento para exame clínico dos pacientes com suspeita de câncer de boca.

Palavras-chave: Neoplasias bucais. Serviços de saúde bucal. Recursos humanos. Recursos humanos em odontologia. Odontologia. Prótese dentária.

\section{Introduction}

Head and neck cancers are global public health problems, with 400 thousand new cases of oral and pharynx cancer every year, 160 thousand cases of larynx cancer, and 300 thousand annual deaths from these cancers around the world ${ }^{1}$.

The incidence of cancer cases of the oral and oropharynx cavities in Brazil is high when compared with that of other countries $^{2}$; among males, incidence rates are above 15.3 cases per 100,000 , similar to rates in the USA, Asia and Australia ${ }^{1}$. As a percentage of all incident cancers (except for non-melanoma skin cancer) in the city of São Paulo in 2010, an estimated $6.36 \%$ of male cancers and $1.52 \%$ of female cancers were of the oral and oropharynx cavities ${ }^{2}$, respectively, the $7^{\text {th }}$ and the $5^{\text {th }}$ cancer type in occurrence ${ }^{2}$.

The most common factors associated with the increase in risk for oral cancer are smoking $^{3}$, alcoholism ${ }^{4,5}$, eating habits ${ }^{6}$ and socioeconomic condition ${ }^{7-9}$. Moreover, the educational role presented by the healthcare team must be considered regarding the prevention of oral cancer and its early diagnosis ${ }^{10}$, increasing the chances of patient survival.

Regarding health services, diagnostic delay is a factor that deserves investigation because prompt care of a patient with suspected oral cancer is crucial in order to offer a favorable prognosis. In the scientific literature, a delay in dental treatment can be classified as: 1) patient's delay, the period between the patient's first symptom and the first appointment with a health professional regarding the symptom described by the patient; and 2) service/professional delay, which corresponds to the period between the patient's first appointment with a health professional and the definite diagnosis ${ }^{11}$.

In a cohort of young oral cancer patients in Scotland, several causes of patient delay were observed, and participants did not suspect that they had oral cancer until it was confirmed by a professional ${ }^{12}$.

Delay in health service accessibility by 
the patient does not have to do only with the patient's delay in looking for treatment because the patient may experience a delay due to the lack of availability of a certain treatment. Thus, the concept of scheduling delay was introduced in order to describe the period between the patient's request for the appointment and the appointment itself, the moment at which the patient would effectively have access to a health professional ${ }^{10,11,13}$. Therefore, our proposal was to study the scheduling delay in suspected cases of oral cancer, assuming that it reflects the degree of professional attention to disease severity and the need for an immediate response by health services.

There are no studies about dental service accessibility in Brazil that have analyzed scheduling delay in the multiple types of services available to the population. In this context, the aim of this study was to evaluate scheduling delay, for patients with suspected oral cancer or in those who need prostheses. Scheduling delay for these patients in a sample of private dental offices and those that accept health insurance in the city of São Paulo was evaluated.

\section{Methods}

A descriptive cross-sectional study was performed using a probabilistic sampling system. Information for the study was based on telephone calls to dental offices in which two different clinical situations, representing two kinds of patients, were simulated. Telephone calls were made from March to July 2007.

Group 1: called "cancer group” (CA), presented symptoms suggesting oral cancer in a 65 year-old male smoker ( 40 cigarettes a month). The symptom described was a painful tongue lesion or ulcer with an evolution of more than 20 days. The investigator would call and, after describing the situation above, would ask when his father (fictitious patient) could be seen.

Group 2: called "prostheses group" (PR), would describe a 60 year-old male seeking prosthodontic treatment. The investigator would ask when his father would be seen in order to replace a removable prosthesis.

Each patient's speech was previously prepared in a written form, in order to assure their pattern. Telephone calls were made by the same investigator on Tuesdays, Wednesdays and Thursdays during business hours, and included summarized initial introduction, reason for the appointment, age, gender, habits, the problem (evolution) and the clinical aspect of the lesion.

A hundred dental clinics were selected in each of the following categories (public, private and those accepting health insurance) for the CA group. The total number of dental clinics was reached by the following statistical patterns for independent data: average sampling 1 and 3 days (these values were based on the findings of López-Jornet and CamachoAlonso ${ }^{11}$ ), referring, respectively, to the mean time for follow-up appointments for CA and PR groups, with standard deviation $=4$, test power $=0.9$ and statistical significance $=0.05$. Fifteen percent $(15 \%)$ more clinics per group were added in order to compensate for losses due to not scheduling consultations.

The dental clinics were randomly drawn; in the case of private dental clinics, the basic initial listing corresponded to the total number of dental clinics in the city of São Paulo listed in the telephone directory, an extensive guide of several products and services. The dental clinics that accepted health insurance were drawn from a list of large health insurance companies in the city. Finally, in the case of public dental offices, the list with dental services was provided by the Municipal Health Department (SMS-SP); telephone scheduling service is available, but patients can also go to the clinic and schedule an appointment. Thus, 3,234 private dental offices, 2,015 offices accepting health insurance and 396 public dental offices were chosen. Without information on dentists' profile, dental offices of each type were listed, and the excel program randomly classified 200 (100 
for CA patients and 100 for PR patients) in each category (private, offices accepting health insurance and public). Furthermore, we did not have information with respect to the offices' routine, and if they had some special day of the week to schedule patients with potentially more urgent situations.

The variables observed in the study were the number of days to schedule the appointment, the type of patient, the type of professional that answered the telephone (dentist or dental assistant in the office) and the type of office (public, private or health insurance). Regarding public dental offices, the analysis was not performed in days to get an appointment but as the type of schedule, emergency or routine. This alternate system was used due to the fact that public dental offices, in their work routine, classify their appointments that way, which allows patients to be assisted in pre-programmed care, such as emergency, in case it is necessary. So, when the hypothetical CA or PR investigator calls to ask for an appointment, public dental offices schedule an initial appointment, and after that, the patient is classified as in need of emergency or routine treatment. Additionally, in public dental offices, neither the dentist nor the dental assistant answers the calls that the office receives.

The mean time from the patient's call to the scheduled appointment corresponded to a dependent variable, and the others, to independent ones. The dependent variable was numerical, and independent variables were categorical. Results were described by means of mean time (number of days) for the scheduling delay and by the percentage of patients that were admitted as "emergency." Data analysis used multivariate negative binomial regression with $95 \%$ statistical significance. The method of regression analysis is considered effective, from a statistical point of view, to compare the count (number of days for scheduling) with high dispersion (higher standard deviation than average) ${ }^{14}$. For each variable analyzed in the multivariate model (patient, dental office and care), the other two variables presented in the study were considered adjustments.

We excluded offices that, after being selected, either did not answer telephone calls made on 3 (three) consecutive days during business hours or no longer used the listed telephone number, as the listed telephone number did not belong to a dental office. In these situations, new clinics were randomly selected. No follow-up appointment was effectively set. One hour after the appointments were scheduled, new telephone calls were made to the dental offices to cancel the appointments. Moreover, once the sample was defined by the telephone directory, as previously mentioned, and in the case of public dental offices, from data provided by SMS -SP (Municipal Health Department), no further information on the professionals who answered the calls was collected. No risks were observed for participating in the study; benefits could be informing dental offices about the importance of reducing scheduling delay among cases suspected of having oral cancer. The project was analyzed and approved by the Ethics Committee of the School of Dentistry, University of São Paulo (protocol number 183/06).

\section{Results}

From a total of 600 dental offices initially selected, 575 participated in the study, representing a total of $95.8 \%$. The 25 dental offices that did not participate, after being selected, refused to schedule the appointment. Actually, difficulties in carrying out the investigation were not observed. Of the dental offices participating in the study, 200 were public, 188 were private and 187 accepted health insurance. Regarding private dental offices, 159 set the appointment; in the offices accepting health insurance, 153 set the appointment for the patient. The dentist answered 125 calls from a total of 375 calls (Table 1 ).

Among the CA patients, the mean time for follow-up was 2.88 days ( $\mathrm{DP}=2.73$ ), and among the PR participants, 4.34 days 
$(\mathrm{DP}=5.94)($ Table 1). Dental offices that worked on private care took less time to set appointments (average of 2.59 days) than the ones with health insurance (2.74 days); additionally, appointments made by dentists tended to be closer to the date of the telephone calls than the ones made by the assistants (media of 2.45 versus 4.21 days, respectively) (Table 1). A one day difference was observed when considering the medians among private and those that accepted health insurance settings (Table 1).
Table 2 shows scheduling delay (in days) of private dental offices and of those accepting health insurance as per group of patients (CA and PR) and regarding appointments made by dentists and assistants.

Table 3 shows the analysis before and after the multivariate adjustment. PR patients were observed to have a $40 \%$ higher delay than CA patients $(\mathrm{p}=0.01)$ in the multivariate analysis. The same table also shows that private dental clinics were $85 \%$

Table 1 - Scheduling delay (in days) of private dental offices and of those accepting health insurance. São Paulo, 2007 Tabela 1 - Demora no agendamento (em dias) em estabelecimentos particulares e de convênio. São Paulo, 2007

\begin{tabular}{|c|c|c|c|c|c|c|}
\hline & $\begin{array}{c}\mathrm{N}^{1} \\
\text { (scheduled }_{\text {appointments) }}\end{array}$ & $\begin{array}{c}\text { Mean } \\
\text { (in days) }\end{array}$ & $\begin{array}{l}\text { Median (in } \\
\text { days) }\end{array}$ & $\begin{array}{l}\text { Standard } \\
\text { Deviation }\end{array}$ & $1^{\circ}$ quartile & $3^{\circ}$ quartile \\
\hline \multicolumn{7}{|l|}{ Patient } \\
\hline With suggestion of oral cancer (CA) & $195(150)$ & 2.88 & 1 & 2.73 & 1 & 5 \\
\hline With need of prostheses (PR) & $180(162)$ & 4.34 & 2 & 5.94 & 1 & 6 \\
\hline \multicolumn{7}{|l|}{ Dental Office } \\
\hline Private & 188 (159) & 2.59 & 1 & 4.10 & 1 & 3 \\
\hline Health Insurance & $187(153)$ & 2.74 & 2 & 5.11 & 1 & 7 \\
\hline \multicolumn{7}{|l|}{ Professional degree } \\
\hline Dentist & $125(100)$ & 2.45 & 1 & 2.55 & 1 & 5 \\
\hline Assistant & $250(212)$ & 4.21 & 2 & 5.40 & 1 & 6 \\
\hline
\end{tabular}

${ }^{1}$ number of dental offices that received telephone calls; ${ }^{2}$ number of dental offices that scheduled the appointment; ${ }^{3}$ mean, in days, of scheduling delay; ${ }^{4}$ median, in days, of scheduling delay.

${ }^{7}$ número de consultórios dentários que receberam telefonemas; ${ }^{2}$ número de consultórios dentários que marcaram a consulta; ${ }^{3}$ média, em dias, de atraso na marcação da consulta; ${ }^{4}$ mediana, em dias, de atraso na marcação.

Table 2 - Scheduling delay (in days) of private dental offices and of those accepting health insurance as per group of patients. São Paulo, 2007

Tabela 2 - Demora no agendamento (em dias) em estabelecimentos particulares e de convênio segundo grupo de pacientes. São Paulo, 2007

\begin{tabular}{|c|c|c|c|c|c|c|}
\hline & \multicolumn{6}{|c|}{ Group of patients } \\
\hline & \multicolumn{3}{|c|}{ With suggestion of oral cancer (CA) } & \multicolumn{3}{|c|}{ With need of prostheses (PR) } \\
\hline & $\begin{array}{c}\mathrm{N}^{1} \\
\text { (scheduled } \\
\text { appointments) }{ }^{2}\end{array}$ & $\begin{array}{c}\text { Mean } \\
\text { (in days) }\end{array}$ & $\begin{array}{l}\text { Median } \\
\text { (in days) }\end{array}$ & $\begin{array}{c}\mathrm{N}^{1} \\
\text { (scheduled } \\
\text { appointments) }{ }^{2}\end{array}$ & $\begin{array}{c}\text { Mean } \\
\text { (in days) }^{3}\end{array}$ & $\begin{array}{c}\text { Median } \\
\text { (in days) }^{4}\end{array}$ \\
\hline Particular & $99(75)$ & 1.94 & 1 & $89(84)$ & 3.15 & 2 \\
\hline Convênio & $96(75)$ & 2.99 & 2 & $91(78)$ & 5.65 & 3 \\
\hline Dentist & $70(60)$ & 2.27 & 1 & $55(40)$ & 2.76 & 1 \\
\hline Assistant & $125(90)$ & 3.37 & 2 & $125(122)$ & 4.80 & 3 \\
\hline
\end{tabular}


faster at making follow-up appointments for patients with suspected cancer $(\mathrm{p}=0.01)$ than the offices that accepted health insurance, and when dentists answered the telephone, the appointment schedule delay was $57 \%$ shorter than when assistants answered the telephone $(\mathrm{p}=0.01)$.

In public dental offices, $69 \%^{57}$ of CA patients were scheduled for an emergency service, compared with $31 \%^{26}$ of the PR patients (Table 4 ), showing a $97 \%$ greater access to dental care for patients suspected of having oral cancer than for patients in need of prostheses $(p=0.01)$.

\section{Discussion}

Studies performed in Liverpool between 1992 and $2004^{15}$, and in Utrecht between
2000 and $2002^{16}$ showed that the scheduling delay may vary from four hours to four months. In the present study, delay in patients for the CA group was 2.88, and for the PR group, 4.34 days.

Although the difference in mean time of scheduling is shown as significant $(p=0.01)$ between the CA and PR patient groups, it does not represent enough of a difference in magnitude to change disease prognosis. Even so, these data show that dental services were accessible with regard to scheduling clinical examinations among patients suspected of having oral cancer. Thus, this finding is relevant for the evaluation of the commitment of dental health professionals to the early diagnosis of cancer.

On the other hand, differences in mean scheduling time in private offices and in

Table 3 - Bivariate and multivariate negative binomial regression of the scheduling delay (in days) of private dental offices and those accepting health insurance. São Paulo, 2007

Tabela 3 - Regressão binomial negativa bivariada e multivariada da demora do agendamento da consulta (em dias) de estabelecimentos particulares e de convênio. São Paulo, 2007

\begin{tabular}{|c|c|c|c|c|c|c|c|}
\hline & \multirow{2}{*}{$\mathrm{N}$} & \multicolumn{3}{|c|}{ Bivariate } & \multicolumn{3}{|c|}{ Multivariate } \\
\hline & & $\mathrm{PR}^{1}$ & $\mathrm{Cl}^{2}(95 \%)$ & $p$ & $\mathrm{PR}^{1}$ & $\mathrm{Cl}^{2}(95 \%)$ & $p$ \\
\hline \multicolumn{8}{|l|}{ Patient } \\
\hline With suggestion of oral cancer (CA) & 195 & 1.00 (ref.) & 1.00 (ref.) & 0.01 & 1.00 (ref.) & 1.00 (ref.) & 0.01 \\
\hline With need of prostheses (PR) & 180 & 1.50 & $1.17-1.93$ & & 1.40 & $1.11-1.78$ & \\
\hline \multicolumn{8}{|l|}{ Dental Office } \\
\hline Private & 188 & 1.00 (ref.) & 1.00 (ref.) & 0.01 & 1.00 (ref.) & 1.00 (ref.) & 0.01 \\
\hline Health Insurance & 187 & 1.82 & $1.37-2.44$ & & 1.85 & $1.43-2.39$ & \\
\hline \multicolumn{8}{|l|}{ Professional degree } \\
\hline Dentist & 125 & 1.00 (ref.) & 1.00 (ref.) & 0.01 & 1.00 (ref.) & 1.00 (ref.) & 0.01 \\
\hline Assistant & 250 & 1.71 & $1.32-2.44$ & & 1.57 & $1.23-2.01$ & \\
\hline
\end{tabular}

Table 4 - Analysis of bivariate negative binomial regression of the type of patient needs and the type of scheduling in public dental offices. São Paulo, 2007

Tabela 4 - Análise da regressão binomial negativa bivariada do tipo de necessidade do paciente e do tipo de agendamento em estabelecimentos públicos. São Paulo, 2007

\begin{tabular}{|c|c|c|c|c|c|c|}
\hline \multirow{3}{*}{$\begin{array}{l}\text { Type of } \\
\text { Scheduling }\end{array}$} & \multicolumn{4}{|c|}{ Group of patients } & \multirow{3}{*}{$\mathrm{PR}^{1}\left(\mathrm{Cl}^{2} 95 \%\right)$} & \multirow{3}{*}{$\mathrm{p}$} \\
\hline & \multicolumn{2}{|c|}{ With suggestion of oral cancer (CA) } & \multicolumn{2}{|c|}{ With need of prosthesis (PR) } & & \\
\hline & $\mathrm{N}$ & $\%$ & $\mathrm{~N}$ & $\%$ & & \\
\hline $\begin{array}{l}\text { Routine } \\
\text { treatment }\end{array}$ & 43 & 36.75 & 74 & 63.25 & 1.00 (ref.) & 0.01 \\
\hline $\begin{array}{l}\text { Urgent } \\
\text { treatment }\end{array}$ & 57 & 68.67 & 26 & 31.33 & $1.97(1.30-2.90)$ & \\
\hline
\end{tabular}

PR: prevalence ratio; ${ }^{2} \mathrm{Cl}$ : confidence interval. / 'PR: razão de prevalência; ${ }^{2} \mathrm{Cl}$ : intervalo de confiança. 
those that accept health insurance were verified; private dental offices showed more promptness in their response to an urgent case than the offices that accepted health insurance. When the data were analyzed as per median, a difference of one day was observed on the scheduling delay between private offices and those that accept health insurance.

In public dental offices, patients suspected of having oral cancer had greater access to dental care than those who needed prostheses given more emergency appointments were scheduled for patients suspected of having oral cancer. Thus, dental offices tend to prioritize care for patients suspected of having oral cancer rather than for patients with another kind of demand that is less severe. More studies are necessary in order to verify the different types of healthcare systems and their relation to referral procedures ${ }^{17}$.

It must also be considered that oral cancer is more common among patients with low socioeconomic condition ${ }^{17}$ and that they depend solely on public health services in Brazil. Our investigation found that $36.75 \%$ of telephone calls made to public offices did not offer care or sent the hypothetical CA patient to screening. This is an impressive finding and it could be related to a low resolution capacity among public health services. Considering that a major proportion of the Brazilian population accesses public health services, one third of them were not scheduled as emergency. More investigations and discussions should be performed with focus exclusively on these services to elucidate the possible reasons for this situation.

Even without information about dentists' profile, we observed a high number of scheduled appointments, showing that professionals are aware of the importance that some specific clinical situations may have on patients' quality of life. The dental clinics whose health professionals answered the phone and did not set the appointment for either suggestion of CA or PR alleged that it was not routine to assist this type of case, and told the supposed patient to look for specialized clinics.

When multivariate adjustment was performed, it slightly modified the results observed in the bivariate analysis. Thus, the variables (type of patient, dental offices and professional degree) were presented as independent variables and interfered very little in the response of the others.

In Spain, the association between scheduling delay and the severity of patient complaint was verified ${ }^{11,13}$. When request for care was justified by signs and compatible symptoms of oral cancer (middle-aged male patient with tongue ulceration), the mean scheduling time was significantly shorter, $1.70(\mathrm{SD}=6.80)$ versus $8.18(\mathrm{SD}=7.5)$ days (prostheses patients) ${ }^{10}$. Our investigation found $2.88(\mathrm{SD}=2.73)$ versus $4.34(\mathrm{SD}=5.94)$ days with regard the same situations.

Although, overall, conditions were favorable to assist cases with suspected oral cancer efficiently, dentists were more apt to realize possible situations of clinical severity in the patient reports than their assistants, given the number of days for follow-up was shorter for the calls that were answered by dentists when compared to the calls that were answered by their assistants. This condition was confirmed by other studies ${ }^{10-11}$. We found that dentists scheduled the CA patient to come to the office within $2.45(\mathrm{SD}=2.55)$ and assistants, within 4.21 ( $\mathrm{SD}=5.40)$ days. López-Jornet and Camacho-Alonso ${ }^{11}$ found that dentists scheduled the appointment after 1.63 $(\mathrm{SD}=1.42)$ the telephone call versus the receptionist, which scheduled it after 3.88 $(\mathrm{SD}=5.57)$ days. Dental clinic assistants are part of the oral health team and must be prepared to differentiate situations reported by patients that can result in different consequences during treatments. They have some attributions, including knowledge about the prevention of oral diseases. For this reason, hopefully they are able to identify, generically, the potential seriousness of the consequences of the patient's complaints. Thus, the results of the study suggest that dental assistants should 
be taught how to differentiate possible urgent situations, especially for patients that present symptoms that are compatible with oral cancer, from routine situations in clinical practice. However, there may be reverse causality if the dentists that answer calls are more available or sensitive to patient demands compared with the ones that do not have time to answer calls, a possibility that may lead to the appearance of a shorter scheduling time for the followup appointment among doctor-scheduled appointments. In our research, there was an attempt to control for this situation by using a multivariate global model, in which private practices, as well as those accepting health insurance, and the professional training of the person answering the phone were analyzed all together.

Complaint severity may be related to the scheduling delay experienced by the patient looking for care. The more severe the complaint/health situation reported, the more likely the suspect of diagnostic identification. A mild symptom may hinder the time to diagnosis by delaying the time to the first appointment. Thus, in a clinical situation, in which patients report few symptoms or fewer specific symptoms, it may be more difficult to make a correct and valid diagnosis. Several investigations have asked dentists if they routinely perform clinical examinations in order to verify possible oral cancer lesions; however, it is not clear exactly what dentists do when they say they perform the examination ${ }^{18}$. When assisting a patient with suspected oral cancer, hopefully the dentist performs a complete anamnesis, examines the patient, performs a biopsy and requests histological analysis of collected material; when findings confirm the suspicion of cancer, the patient must be sent to a specialized service, and the dentist should advise him about the emergency that the clinical situation requires ${ }^{19}$. When the dentist does not feel confident to perform the biopsy, the patient must be sent to a specialist who will perform the necessary procedures to elucidate the diagnosis and will follow the case with an oncology team.

The potential limitations of this study include lack of information regarding the profile of dentists that answered the phones, and, also, of the dental offices whose professionals did not answer three telephone calls during business hours and that were considered losses. Additionally, the study was performed in the city of São Paulo, which offers many oncology services and substantial educational information about oral cancer prevention; more studies are necessary in order to verify whether the results would be similar if the research were carried out in other parts of the country.

Another possible limitation of the study is that it was performed in order to guarantee a representative sample in each study group. This decision may not have guaranteed group proportionality among groups, making it difficult to generalize the results. Furthermore, a possible selection bias may have been present, considering that some dental offices may not be part of the telephone directory used in the sampling procedures.

\section{Conclusion}

In short, the dental care system showed a broader accessibility to patients suspected of having cancer, even though the difference in the number of days of scheduling delay was low. The fact that the difference is significant suggests that dentists are alert to the need to provide prompt diagnoses for patients whose clinical situation is urgent. However, dental clinic assistants should be better trained in order to act the same way. Public health services must be prepared to increase the accessibility of potential oral cancer patients.

Acknowledgment: To Fundação de Amparo à Pesquisa do Estado de São Paulo (FAPESP) for the support to carry out this research (Process number 06/07079-8). 


\section{References}

1. Boyle P, Levin B (Eds.). World cancer report 2008. Lyon: IARC Press; 2008.

2. Brasil. Ministério da Saúde. Secretaria de Atenção à Saúde. Instituto Nacional do Câncer. Coordenação de Prevenção e Vigilância de Câncer. Estimativa 2010: Incidência de Câncer no Brasil. Rio de Janeiro: INCA, 2009.

3. Döbróssy L. Epidemiology of head neck cancer: magnitude of the problem. Cancer Metastasis Rev 2005; 2(1): 9-17.

4. Fioretti F, Bosetti C, Tavani A, Franceschi S, La Vecchia C. Risk factors for oral and pharyngeal cancer in never smokers. Oral Oncol 1999; 35: 375-8.

5. Ogden GR. Alcohol and oral cancer. Alcohol 2005; 35(3): 169-73.

6. Zain RB. Cultural and dietary risk factors of oral cancer and precancer - a brief overview. Oral Oncol 2001; 37: 205-10.

7. Antunes JLF, Biazevic MGH. Araujo ME, Tomita NE, Chinellato L, Narvai PC. Trends and spatial patterns of oral cancer mortality in São Paulo, Brazil, 1980-1998. Oral Oncol 2001;37: 345-50.

8. Biazevic MGH, Antunes JLF, Castellanos-Fernandez RA, Michel-Crosato, E. Tendências de mortalidade por câncer de boca e orofaringe no município de São Paulo, 1980-2002. Cad Saúde Pública 2006; 22: 2105-14.

9. Hashibe M, Jacob BJ, Thomas G, Ramadas K, Mathew B, Sankaranarayanan R, Zhang ZF. Socioeconomic status, lifestyle factors and oral premalignant lesions. Oral Oncol 2003; 39(7): 664-71.

10. Diz-Dios P, González JP, Lestón JS, Carmona IT, Posse JL, Varela-Centelles P. "Scheduling delay" in oral cancer diagnosis: a new protagonist. Oral Oncol 2005; 41: 142-6.
11. López-Jornet P, Camacho-Alonso F. New barriers in oral cancer. Pacient accessibility to dental examination - a pilot study. Oral Oncol 2006; 42(10): 1022-1025

12. Grant E, Silver K, Bauld L, Day R, Warsulasuriya S. The experiences of young oral cancer patients in Scotland: symptom recognition and delays in seeking professional help. Br Dent J 2010; 208(10): 465-71.

13. McLeod NMH, Saeed NR, Ali EA. Oral cancer: delays in referral and diagnosis persist. Br Dent J 2005; 198(11): 681-4.

14. Long J. Scott. Regression models for categorical and limited dependent variables. Thousand Oaks, California: Sage Publications; 1997.

15. Rogers SN, Pabla R, McSorley A, Lowe D, Brown JS,Vaughan ED. An assessment of deprivation as a factor in the delays in presentation, diagnosis and treatment in patients with oral and oropharyngeal squamous cell carcinoma. Oral Oncol 2007; 43(7): 648-55.

16. Brouha XDR, Tromp DM, Koole R, Hordijk GJ, Winnubst JAM, Leeuw JRJ. Professional delay in head and neck cancer patients: Analysis of the diagnostic pathway. Oral Oncol 2007; 43(6): 551-6.

17. Gómez I, Warsulasuriya S, Varela-Centelles PI, LópezJornet P, Suárez-Cunqueiro M, Diz-Dios P, Seoane J. Is early diagnosis of oral cancer a feasible objective? Who is to blame for diagnostic delay? Oral Dis 2010; 16(4): 33342 .

18. Lehew CW, Epstein JB, Kaste LM, Choi YK. Assessing oral cancer early detection: clarifying dentists' practices. $J$ Public Health Dent 2009 Sep 17. [Epub ahead of print].

19. Neville BW, Day TA. Oral cancer and precancerous lesions. CA Cancer J Clin 2002; 52: 195-215.

Recebido em: 13/04/2010 Versão final apresentada em: 11/02/2011 Aprovado em: 23/08/2011 